\title{
Effectiveness of Multi-Criteria Optimization- based Trade-Off exploration in combination with RapidPlan for head \& neck radiotherapy planning
}

\author{
Eliane Miguel-Chumacero* (D), Garry Currie, Abigail Johnston and Suzanne Currie
}

\begin{abstract}
Background: A new strategy is introduced combining the use of Multi-Criteria Optimization-based Trade-Off Exploration (TO) and RapidPlan ${ }^{T M}$ (RP) for the selection of optimisation parameters that improve the trade-off between sparing of organs at risk (OAR) and target coverage for head and neck radiotherapy planning. Using both approaches simultaneously; three different workflows were proposed for the optimisation process of volumetric-modulated arc therapy (VMAT) plans. The generated plans were compared to the clinical plans and the plans that resulted using $\mathrm{RP}$ and TO individually.
\end{abstract}

Methods: Twenty clinical VMAT plans previously administered were selected. Five additional plans were created for each patient: a clinical plan further optimised with TO (Clin+TO); two plans generated by in-house built RP models, RP_1 with the model built with VMAT clinical plans and RP_TO with the model built with VMAT plans optimised by TO. Finally, these last two plans were additionally optimised with TO for the creation of the plans RP_1 + TO and RP_TO ${ }^{+}$ respectively. The TO management was standardised to maximise the sparing of the parotid glands without compromising a clinically acceptable PTV coverage. Resulting plans were inter-compared based on dose-volume parameters for OAR and PTVs, target homogeneity, conformity, and plans complexity and deliverability.

Results: The plans optimised using TO in combination with RP showed significantly improved OAR sparing while maintaining comparable target dose coverage to the clinical plans. The largest OAR sparing compared to the clinical plans was achieved by the RP_TO ${ }^{+}$plans, which reported a mean parotid dose average of $15.0 \pm 4.6 \mathrm{~Gy}$ vs $22.9 \pm 5.5 \mathrm{~Gy}$ (left) and $17.1 \pm 5.0 \mathrm{~Gy}$ vs $24.8 \pm 5.8 \mathrm{~Gy}$ (right). However, at the same time, RP_TO showed a slight dose reduction for the 99\% volume of the nodal PTV and an increase for the 95\% (when comparing to the clinical plans $76.0 \pm 1.2$ vs $77.4 \pm 0.6$ and $80.9 \pm 0.9$ vs $79.7 \pm 0.4$ ) but remained within clinical acceptance. Plans optimised with RP and TO combined, showed an increase in complexity but were proven to be deliverable.

Conclusion: The use of TO combined with RP during the optimisation of VMAT plans enhanced plan quality the most. For the RP_TO ${ }^{+}$plans, acceptance of a slight deterioration in nodal PTV allowed the largest reduction in OAR dose to be achieved.

Keywords: Multi-criteria optimisation, Trade-offs exploration, Head and neck cancer, Knowledge-based treatment planning, RapidPlan, Volumetric-modulated arc therapy

\footnotetext{
* Correspondence: Eliane.Miguel@ggc.scot.nhs.uk

Beatson West of Scotland Cancer Centre, Radiotherapy Physics, NHS Greater

Glasgow and Clyde, 1053 Great Western Road, Glasgow G12 OYN, UK
}

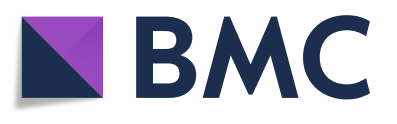

(C) The Author(s). 2018 Open Access This article is distributed under the terms of the Creative Commons Attribution 4.0 International License (http://creativecommons.org/licenses/by/4.0/), which permits unrestricted use, distribution, and

reproduction in any medium, provided you give appropriate credit to the original author(s) and the source, provide a link to the Creative Commons license, and indicate if changes were made. The Creative Commons Public Domain Dedication waiver (http://creativecommons.org/publicdomain/zero/1.0/) applies to the data made available in this article, unless otherwise stated. 


\section{Background}

The challenge in radiotherapy planning is to manage the compromise between tumour irradiation and sparing of healthy tissue. The planning objectives involved can be inherently contradictory, which restricts an optimal result for all objectives at the same time. This situation is reflected in the irradiation of head and neck cancer (HNC) where there are many organs at risk (OAR) and their close proximity to the target volume makes it difficult to achieve clinically acceptable target coverage without radiation-induced toxicity and decreased of quality of life [1-3].

For the treatment of HNC, volumetric-modulated arc therapy (VMAT) has shown good dose conformity and sparing of OAR with a decrease in treatment delivery time compared to other techniques [4-7]. For this inverse planning technique, the desired dose is prescribed for the planning target volume (PTV) and for the surrounding structures the tolerated dose is defined; then through an iterative optimisation process a plan is computed. The optimisation result is the plan which best achieves the stated objectives by minimising a cost function associated with them. However, this result is often not satisfactory since the compromise between the planning goals might not be clinically acceptable and the optimisation objectives may not adequately describe the clinical situation. Different objective settings are tried until an acceptable solution is found, which is time consuming and may result in sub-optimal treatment plans. For the solution of this inverse problem, a Multi-Criteria Optimisation (MCO) approach has been proposed as a more efficient method [8-15]. Whereas single objective function optimisation problems have one best solution, in $\mathrm{MCO}$ a vector of objective functions is optimised resulting in many best-compromised solutions that describe a mathematical construct, an approximation of the Pareto surface. In practice this is composed of alternative plans that are created, where each of them will prioritise a specific optimisation objective over all others. Therefore, each alternative plan is optimal in that one objective can only be improved by deteriorating others [16].

Eclipse treatment planning system (TPS) Varian Medical Systems, Palo Alto, CA, version 15.5 introduces the tools for a MCO approach based on trade-offs exploration (TO). A copy of an initial plan optimisation, called the balanced plan, is used together with the chosen $\mathrm{N}$ optimisation objectives as the base for the subsequent generation of the $3 \mathrm{~N}+1$ alternative plans for objective. The user can then explore the trade-offs along the possible solutions and select the plan that best fulfils the treatment goals. The initial plan influences the subsequent Pareto frontier approximation, therefore, trade-offs exploration around a starting promising plan is desirable $[16,17]$.
Recently, knowledge-based radiotherapy treatment planning has been incorporated into clinical practice. $\operatorname{RapidPlan}^{\mathrm{TM}}$ (RP) (Eclipse v15.5) operates with a knowledge-based treatment planning algorithm that is able to generate dose volume histogram (DVH) estimates for a new patient geometry by analysis of a database of previous plans. The DVH estimates are then translated into optimisation objectives parameters for intensity modulated radiotherapy (IMRT) or VMAT plans. The resulting plans have shown to reduce planner interaction while improving the quality and consistency $[18,19]$. However, the quality of the plans generated for new patients depends highly on the quality and robustness of the plans in the training cohort [20].

In this study the key question addressed was how to maximise the performance of $\mathrm{RP}$ and $\mathrm{TO}$ for the radiotherapy treatment of $\mathrm{HNC}$. We suggested a combination of both approaches, RP and TO used simultaneously during the optimisation process of a plan. Three different workflows were proposed for the VMAT planning of HNC patients and an inter-comparison of the resulting plans was performed. At the same time, these were compared with the plans optimised using RP and TO on their own and the clinical plans for reference.

\section{Methods \\ Patient data}

Clinical HNC plans previously administered were available from a database with tumours originating in various sites and stages, i.e. tongue, glottis, supraglottis, lip, oral cavity, nasal cavity, tonsillar region, larynx, pharynx (oro, hypo and naso), neck and parotids. Plans for the region of optical structures were not included. The clinical plans were generated with the in-house optimisation template (based on the plan constraints shown on Table 1) and expert planners modified the optimisation parameters as necessary. The planned target volumes were: the main tumour (PTV1), and neck nodes encompassed by the low-risk planning treatment volume (PTVLR). Dose levels of $65 \mathrm{~Gy}$ and $54 \mathrm{~Gy}$ in 30 fractions were respectively prescribed. Both PTVs were created with $3-5 \mathrm{~mm}$ margins from the Clinical Target Volume (CTV). Planning organ at risk volumes (PRVs) were used for spinal cord and brainstem by expanding from these structures. The planning technique was the Varian VMAT solution RapidArc ${ }^{\mathrm{TM}}$, utilising 2 full coplanar arcs with the collimator rotated to 30 and 330 degrees, and $6 \mathrm{MV}$ photons. Plan calculations were made using the Eclipse $^{\mathrm{Tm}}$ Photon Optimiser and Anisotropic Analytic Algorithm version 15.5.07. Aperture Shape Control 
Table 1 Dose-volume constraints for the PTVs and OAR

\begin{tabular}{ll}
\hline PTV/Organ & Dose-Volume constraint \\
\hline PTV1 (65Gy prescribed in 30 fractions) & $99 \%$ volume more than $90 \%$ of the dose \\
& $95 \%$ volume more than $95 \%$ of the dose \\
& $5 \%$ volume less than $105 \%$ of the dose \\
& $2 \%$ volume less than $107 \%$ of the dose \\
& $99 \%$ volume more than $90 \%$ of the dose \\
PTVLR (54Gy prescribed in 30 fractions) & $95 \%$ volume more than $95 \%$ of the dose \\
& The dose for $1 \%$ of the volume is limited to 44 Gy and no part should receive more than 48 Gy \\
PRV Spinal cord & 48 Gy was restricted to no more than $1 \%$ of the volume \\
PRV Brainstem & 50 Gy was restricted to no more than $1 \%$ of the volume \\
Optic Nerve & 50 Gy was restricted to no more than $1 \%$ of the volume \\
Optic Chiasm & The maximum mean dose is limited to 24 Gy \\
Parotids & The maximum mean dose is limited to 40 Gy \\
Larynx &
\end{tabular}

was set to "Moderate" and all had the same Normal Tissue Objectives (NTO). The target volumes and OAR constraints followed in this study for all the sets of plans are shown on Table 1 and are based on the Phase 3 PARSPORT trial specifications [21, 22].

Two different sets of plans were used in this work. Set_1 consisted of a collection of 54 plans that were selected randomly from the database for the creation of the RP models described in the methods section part III. These plans had a mean PTV1 volume of $325.0 \mathrm{cc}$ (range $68.6-786.6 \mathrm{cc}$ ) and mean PTVLR volume of $182.0 \mathrm{cc}$ (range 0-375.7 cc).

Set_2 included 20 different patients; these had a mean PTV1 volume of $291.8 \mathrm{cc}$ (range $75.5-1069.4 \mathrm{cc}$ ) and a mean PTVLR volume of 274.2 cc (range 124.7-389.0 cc). Set_2 was selected from cases with no full parotid involvement (2 Tonsil, 6 Larynx, 5 Pharynx, 5 oral, and 2 face), with mean volume overlap of parotids and PTVs of $19.9 \%$, (range $0-40.8 \%$ ). Set 2 was used for the creation, comparison, and analysis of plans using TO and/ or RP.

\section{Trade-offs exploration optimisation}

The inclusion of MCO in radiotherapy planning aims to allow the exploration of the trade-offs of the treatment objectives in an efficient way to then select a plan that best fulfils the prescribed clinical goals. To commence, it is required to have a starting plan (that will be the centre of the approximation of the Pareto surface). The optimisation objectives used in inverse radiotherapy planning are based on dose statistics to regions of interest, for instance:

- Upper or lower objectives: dose-volume points that define the maximum or minimum dose that a structure may receive.
- Mean objective: mean dose level that should not be exceeded for a structure.

- Line objective: it is located under the lower bound of the DVH estimate range. If the OAR overlaps with the target, the highest upper objective of the target is the defining level in that region.

A starting plan will be used together with a selection of the optimisation objectives for trade-off exploration as the base for a generation of alternative plans.

The optimisation objectives selected for the tradeoff exploration of this study were: right and left parotids line dose or mean dose (for the Clinical plans), PRV brainstem upper point $\left(D_{\max }\right), \quad$ PRV spinal cord combined (upper points $D_{1}$ and $D_{\max }$ ), and larynx line dose only when the tumour did not originate in it. Upper and lower point objectives were selected for PTV1 and lower point objectives for PTVLR [23].

After the calculation of the alternative plans, a slider for each selected objective is displayed. The sliders represent the range for the objective covered by the balanced and alternative plans. A selector in the slider can be manipulated to explore the trade-offs, when it is moved to the left the associated objective improves. The manipulation of one slider automatically affects the position of other selectors depending on the trade-offs. If the planner wants to restrict the range of a specific objective a component in the slider called restrictor is used, this keeps the selector within the new range influencing how the cost is distributed during the trade-off exploration; otherwise, the algorithm aims to distribute the cost of the improvement evenly among other criteria [16]. The feedback of the exploration was constantly monitored through visual assessment of the DVHs, an axial view of the dose distribution on patient 
anatomy, and in the clinical protocol attached to the plan (see Fig. 5 in Appendix). Once satisfied with the result, the DVHs and the spatial distribution of the dose that resulted from the trade-offs were used as optimisation objectives parameters for the creation of a deliverable VMAT plan and the final dose was calculated.

We prioritised a dosimetric reduction on the parotid glands [24-26]. Therefore, on the alternative plans that were generated, the management of the trade-offs was standardised as follows:

1. A restrictor to stop further dose increase to spinal cord and brainstem was applied; this action still allowed their initial dose to reduce as a consequence of other structures improvement.

2. The mean dose to right and left parotids was reduced. The limit for this was meeting the prescribed dose constraints for the PTVs.

3. Mean dose to larynx was reduced with the least importance over the other organs and only when its effect would not compromise the target constraints.

To begin the study, Set_2 plans were selected as the starting plans and optimised with $\mathrm{TO}$ to create the Clin+TO plans following the procedure described above.

\section{RapidPlan with trade-offs optimisation}

For RapidPlan knowledge-based planning a model needs to be created. The model configuration comprises two phases: data extraction and model training. During the first phase, the data related to the structure set, dose, and field geometry of each plan included is extracted; this information is used to train the model which will then estimate DVHs for a new plan based on the information obtained from the data set of plans [27].

Once the model is trained, it will be used together with the structure set of the new plan and the dose specifications for the target to provide a DVH estimation range for each of the OAR; also it will provide the optimisation objectives parameters needed to try to achieve the estimation.

Two RP models for HNC were generated using the dosimetric and geometric data from Set_1. The first model (RP_1) was trained with the 54 standard clinical VMAT plans. The second model (RP_TO) used the same VMAT plans but this time further optimisation was carried out using TO (following the process in Section II) prior to adding them to the model. Set_1 consisted of plans previously used for the head and neck RP model that is currently in use at our clinic, therefore, these plans are clinically acceptable and the model was processed for elimination of outliers. Both models were generated by training the two PTV targets and 12 OAR structures (PRV brainstem, larynx, lenses, optic nerves, orbits, parotids, PRV spinal cord, and trachea). The optimisation objectives selected are shown in Table 5 in Appendix.

The two models were used to generate a plan for each patient of Set 2 without manual intervention, RP_1 and RP_TO. The resulting plans were then used as the initial plans for a further optimisation using TO for the creation of the last two types of plans for each patient, $\mathrm{RP} \_1+\mathrm{TO}$ and $\mathrm{RP}_{-} \mathrm{TO}^{+}$ (following the same trade-offs exploration procedure described on section II). In this way, the trained models suggested the optimisation objectives parameters for an initial plan that would be the centre of the later approximation of the Pareto surface. Figure 1 summarizes the workflows used for the generation of the plans created for this study. All plans from this part and section II were normalized $100 \%$ to target mean, and the dosimetric data was collected.

\section{Data comparison and analysis}

For the clinical plans and the 5 different plans generated for each patient, PTVs and OAR doses were evaluated following the dose-volume constraints specified. Additionally, the homogeneity of the PTVs was assessed by calculating the Homogeneity Index according to Eq. 1 [28].

$$
H I=\left(\frac{D_{5 \%}}{D_{95 \%}}\right)
$$

Also, the dose delivered to normal tissue was assessed by Eq. 2 [29].

$$
\text { Conformity Index }(C I)=\frac{V x \%}{V P T V S}
$$

Where $\mathrm{V} x \%$ is the volume receiving at least $\mathrm{x} \%$ of the dose and VPTVs is the sum of both target volumes PTV1 and PTVLR. This was calculated for V100\%, V80\%, V50\%, and V10\%.

To investigate plan deliverability, RadCalc version 6.3 was used to quantify several complexity parameters: the total number of monitor units (MU), the modulation factor (MF) and the average leaf pair opening (ALPO) [30, 31].

For the plans that resulted in lowest MF, plan specific quality assurance (QA) measurements were 


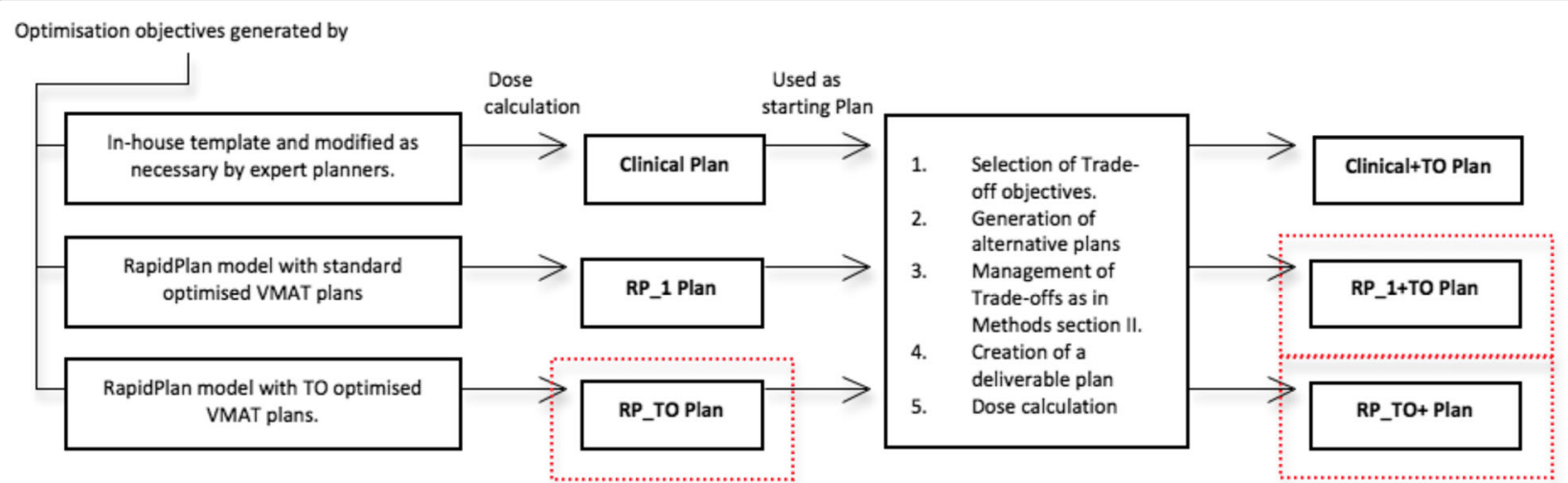

Fig. 1 Planning workflow of: Clinical, Clinical+TO, RP_1, RP_1 + TO, RP_TO, and RP_TO+. (See in red proposed workflows)

performed at the treatment room for further evaluation of the delivered dose. A Varian TrueBeam Slim linear accelerator was used and the phantom Octavius 729 detector array together with the Octavius 4D rotating unit. A comparison between the delivered and the planned dose was performed with a $3 \mathrm{D}$ gamma evaluation (global and local) using the verification software VeriSoft 6.1 (6.1.0.46) and an acceptance of $95 \%$ points passing the criteria of $3 \mathrm{~mm}$ for the distance to agreement (DTA) and a dose difference tolerance level of $3 \%[32,33]$. For all above comparative analysis, the threshold for inclusion was set at $10 \%$ of the maximum dose.

Significant differences between the 6 final sets of plans were assessed for all the investigated parameters by the Wilcoxon signed-rank test at a level of 0.05 .

\section{Results}

\section{Dosimetric evaluation}

All plans resulting from implementing $\mathrm{TO}$ and/or $\mathrm{RP}$ were deemed clinically acceptable according to the criteria of PTV coverage and OAR doses (Table $1)$. While maintaining comparable target coverage, the sparing of the OAR improved. Table 2 lists the dosimetric parameter values (average \pm standard deviation) obtained for the PTVs and OAR for the HNC plan sets following each of the 5 planning procedures described, and for the clinical plans; the letters indicate significant difference at a level of 0.05 when inter-comparing these techniques. The HI, $\mathrm{CI}$, and the number of parameters that failed to meet the constraints for each procedure, and the number of plans that correspond to these failures, are also displayed (for further detail see Table 6 in Appendix). Additionally, doses were investigated for larynx and trachea and are reported in Table 7 in Appendix.
For the plans created, it is shown in Table 2 that PTV1 reported no statistically significant dose reduction compared to the clinical plans for its 99 and $95 \%$ volumes $\left(D_{99}, D_{95}\right)$ and the homogeneity index remained comparable across techniques as well. For PTVLR, the dose homogeneity was shown to be slightly affected and $D_{95}$ increased significantly but a $D_{99}$ significant reduction resulted only for RP_TO $\mathrm{TO}^{+}$.

Figure 2 presents the dose differences obtained between the clinical plan and the other five plans created for each of the 20 patients. It is shown that the largest OAR reductions were achieved when RP and TO were implemented together, with the largest sparing for brainstem, parotid glands, and spinal cord being achieved by the $\mathrm{RP}_{-} \mathrm{TO}^{+}$plans. For OAR, RP_1 + TO and RP_TO reported no significant difference between them. Furthermore, the combined use of RP and $\mathrm{TO}$ showed improvements in $\mathrm{CI}$ when comparing with the solely use of TO (Clin+TO plans) however whereas RP_TO plans are comparable with the clinical plans, for RP_1+TO and RP_TO ${ }^{+}$the results showed an increase. The dose distribution of a representative case is illustrated in Fig. 3, which displays all plans at the parotid level. Figure 4 shows the DVHs corresponding to the patient plans shown in Fig. 3.

\section{Complexity parameters evaluation}

Table 3 displays the average values (and range) of the complexity parameters assessed for each group of plans. The clinical, RP_1 and Clin+TO plans, when compared, showed no significant differences in the number of MU or the MF. However, the use of $\mathrm{TO}$ and RP together in the three remaining types of plans led to an increase in MU and a decrease in the MF, indicating a higher complexity of the plan. 
Table 2 Summary of average \pm s.d. doses to PTVs and OAR for the 20 patients in Set_2

\begin{tabular}{|c|c|c|c|c|c|c|c|}
\hline Structure & Parameter & a - Clinical & $\mathrm{b}-$ Clinical $+\mathrm{TO}$ & $c$ - RP_1 & $d-R_{-} \_1+T O$ & e - RP_TO & $f-\mathrm{RP}_{-} \mathrm{TO}^{+}$ \\
\hline \multirow[t]{5}{*}{ PTV 1} & $\begin{array}{l}D_{99 \%}>90 \% \\
p<0.05\end{array}$ & $\begin{array}{l}93.7 \pm 0.9 \\
c\end{array}$ & $94.1 \pm 2.0$ & $\begin{array}{l}94.2 \pm 1.2 \\
a, e\end{array}$ & $93.8 \pm 2.5$ & $\begin{array}{l}93.6 \pm 1.5 \\
c\end{array}$ & $93.7 \pm 2.3$ \\
\hline & $\begin{array}{l}D_{95 \%}>95 \% \\
p<0.05\end{array}$ & $\begin{array}{l}96.1 \pm 0.6 \\
b, c, d\end{array}$ & $\begin{array}{l}96.8 \pm 0.8 \\
a, c, e, f\end{array}$ & $\begin{array}{l}96.3 \pm 0.7 \\
a, b, e\end{array}$ & $\begin{array}{l}96.6 \pm 1.0 \\
a, e\end{array}$ & $\begin{array}{l}96.0 \pm 0.9 \\
b, c, d, f\end{array}$ & $\begin{array}{l}96.4 \pm 0.9 \\
b, e\end{array}$ \\
\hline & $\begin{array}{l}D_{5 \%}<105 \% \\
p<0.05\end{array}$ & $\begin{array}{l}102.9 \pm 0.5 \\
b, d\end{array}$ & $\begin{array}{l}102.4 \pm 0.5 \\
a, c, e, f\end{array}$ & $\begin{array}{l}102.7 \pm 0.4 \\
b, d, e\end{array}$ & $\begin{array}{l}102.4 \pm 0.7 \\
a, c, e, f\end{array}$ & $\begin{array}{l}103.1 \pm 0.6 \\
b, c, d\end{array}$ & $\begin{array}{l}102.8 \pm 0.8 \\
b, d\end{array}$ \\
\hline & $\begin{array}{l}D_{2 \%}<107 \% \\
p<0.05\end{array}$ & $\begin{array}{l}103.5 \pm 0.7 \\
b, d, e\end{array}$ & $\begin{array}{l}103.0 \pm 0.8 \\
a, c, e, f\end{array}$ & $\begin{array}{l}103.4 \pm 0.6 \\
b, e\end{array}$ & $\begin{array}{l}103.5 \pm 0.9 \\
a, e, f\end{array}$ & $\begin{array}{l}103.8 \pm 0.8 \\
a, b, c, d\end{array}$ & $\begin{array}{l}103.7 \pm 1.2 \\
b, d\end{array}$ \\
\hline & $\begin{array}{l}\mathrm{HI} \\
p<0.05\end{array}$ & $\begin{array}{l}1.07 \pm 0.01 \\
b, c, d\end{array}$ & $\begin{array}{l}1.06 \pm 0.01 \\
a, c, e, f\end{array}$ & $\begin{array}{l}1.07 \pm 0.01 \\
a, b, d, e\end{array}$ & $\begin{array}{l}1.06 \pm 0.02 \\
a, e, f\end{array}$ & $\begin{array}{l}1.07 \pm 0.01 \\
b, c, d, f\end{array}$ & $\begin{array}{l}1.07 \pm 0.02 \\
b, d, e\end{array}$ \\
\hline \multirow[t]{3}{*}{ PTV LR } & $\begin{array}{l}D_{99 \%}>74.8 \% \\
p<0.05\end{array}$ & $\begin{array}{l}77.4 \pm 0.6 \\
c, f\end{array}$ & $\begin{array}{l}77.1 \pm 1.0 \\
c, f\end{array}$ & $\begin{array}{l}78.4 \pm 0.7 \\
a, b, d, e, f\end{array}$ & $\begin{array}{l}77.0 \pm 1.4 \\
c, f\end{array}$ & $\begin{array}{l}77.5 \pm 1.0 \\
c, f\end{array}$ & $\begin{array}{l}76.0 \pm 1.2 \\
a, b, c, d, e\end{array}$ \\
\hline & $\begin{array}{l}D_{95 \%}>78.9 \% \\
p<0.05\end{array}$ & $\begin{array}{l}79.7 \pm 0.4 \\
b, c, d, f\end{array}$ & $\begin{array}{l}81.1 \pm 0.9 \\
\mathrm{a}, \mathrm{c}, \mathrm{e}\end{array}$ & $\begin{array}{l}80.2 \pm 0.5 \\
a, b, d, e, f\end{array}$ & $\begin{array}{l}81.2 \pm 0.6 \\
a, c, e\end{array}$ & $\begin{array}{l}79.9 \pm 0.6 \\
b, c, d, f\end{array}$ & $\begin{array}{l}80.8 \pm 0.9 \\
\mathrm{a}, \mathrm{c}, \mathrm{e}\end{array}$ \\
\hline & $\begin{array}{l}\mathrm{HI} \\
p<0.05\end{array}$ & $\begin{array}{l}1.13 \pm 0.02 \\
b, c, d, f\end{array}$ & $\begin{array}{l}1.16 \pm 0.02 \\
a, c, e, f\end{array}$ & $\begin{array}{l}1.12 \pm 0.01 \\
a, b, d, e, f\end{array}$ & $\begin{array}{l}1.16 \pm 0.02 \\
a, c, e, f\end{array}$ & $\begin{array}{l}1.13 \pm 0.01 \\
b, c, d, f\end{array}$ & $\begin{array}{l}1.17 \pm 0.02 \\
a, b, c, d, e\end{array}$ \\
\hline PRV Brainstem & $\begin{array}{l}\mathrm{D}_{\operatorname{Max}}<48 \mathrm{~Gy} \\
p<0.05\end{array}$ & $\begin{array}{l}26.9 \pm 15.7 \\
b, c, d, e, f\end{array}$ & $\begin{array}{l}24.3 \pm 14.5 \\
a, f\end{array}$ & $\begin{array}{l}25.9 \pm 14.8 \\
\mathrm{a}, \mathrm{d}, \mathrm{e}, \mathrm{f}\end{array}$ & $\begin{array}{l}23.2 \pm 13.3 \\
a_{1} c_{1}\end{array}$ & $\begin{array}{l}23.9 \pm 13.5 \\
\mathrm{a}, \mathrm{c}, \mathrm{f}\end{array}$ & $\begin{array}{l}20.9 \pm 11.6 \\
a, b, c, e\end{array}$ \\
\hline \multirow[t]{2}{*}{ PRV Spinal Cord } & $\begin{array}{l}D_{1 \%}<44 G y \\
p<0.05\end{array}$ & $\begin{array}{l}37.6 \pm 2.7 \\
b, c, d, e, f\end{array}$ & $\begin{array}{l}32.7 \pm 2.9 \\
a, c, d, f\end{array}$ & $\begin{array}{l}36.4 \pm 2.2 \\
a, b, d, e, f\end{array}$ & $\begin{array}{l}30.5 \pm 3.1 \\
a, b, c, f\end{array}$ & $\begin{array}{l}31.5 \pm 3.0 \\
a, c, f\end{array}$ & $\begin{array}{l}27.5 \pm 4.7 \\
a, b, c, d, e\end{array}$ \\
\hline & $\begin{array}{l}\mathrm{D}_{\text {Max }}<48 \mathrm{~Gy} \\
p<0.05\end{array}$ & $\begin{array}{l}40.4 \pm 2.9 \\
b, d, e, f\end{array}$ & $\begin{array}{l}35.1 \pm 2.9 \\
a, c, f\end{array}$ & $\begin{array}{l}39.3 \pm 2.2 \\
b, d, e, f\end{array}$ & $\begin{array}{l}33.6 \pm 3.4 \\
a, c, f\end{array}$ & $\begin{array}{l}34.3 \pm 3.5 \\
a, c, f\end{array}$ & $\begin{array}{l}30.8 \pm 4.9 \\
a, b, c, d, e\end{array}$ \\
\hline Left Parotid & $\begin{array}{l}\mathrm{D}_{\text {Mean }}<24 \mathrm{~Gy} \\
p<0.05\end{array}$ & $\begin{array}{l}22.9 \pm 5.5 \\
b, d, e, f\end{array}$ & $\begin{array}{l}16.7 \pm 4.8 \\
a, c, f\end{array}$ & $\begin{array}{l}22.3 \pm 5.5 \\
b, d, e, f\end{array}$ & $\begin{array}{l}16.7 \pm 4.5 \\
a, c, f\end{array}$ & $\begin{array}{l}16.8 \pm 4.9 \\
a, c, f\end{array}$ & $\begin{array}{l}15.0 \pm 4.6 \\
a, b, c, d, e\end{array}$ \\
\hline Right Parotid & $\begin{array}{l}\mathrm{D}_{\text {Mean }}<24 \mathrm{~Gy} \\
p<0.05\end{array}$ & $\begin{array}{l}24.8 \pm 5.8 \\
b, d, e, f\end{array}$ & $\begin{array}{l}19.1 \pm 4.4 \\
a, c, f\end{array}$ & $\begin{array}{l}24.2 \pm 5.4 \\
b, d, e, f\end{array}$ & $\begin{array}{l}18.4 \pm 4.7 \\
a, c, f\end{array}$ & $\begin{array}{l}19.0 \pm 5.9 \\
a, c, f\end{array}$ & $\begin{array}{l}17.1 \pm 5.0 \\
a, b, c, d, e\end{array}$ \\
\hline \multirow[t]{4}{*}{$\mathrm{Cl}$} & $\begin{array}{l}\text { V100\%/NPTVs } \\
p<0.05\end{array}$ & $\begin{array}{l}0.27 \pm 0.08 \\
b, d\end{array}$ & $\begin{array}{l}0.29 \pm 0.09 \\
a, c, e\end{array}$ & $\begin{array}{l}0.27 \pm 0.08 \\
b, d, f\end{array}$ & $\begin{array}{l}0.29 \pm 0.09 \\
a, c\end{array}$ & $\begin{array}{l}0.28 \pm 0.09 \\
b\end{array}$ & $\begin{array}{l}0.29 \pm 0.09 \\
c_{1}\end{array}$ \\
\hline & $\begin{array}{l}\text { V80\%/NPTVs } \\
p<0.05\end{array}$ & $\begin{array}{l}1.26 \pm 0.14 \\
b, d, f\end{array}$ & $\begin{array}{l}1.47 \pm 0.15 \\
a, c, d, e, f\end{array}$ & $\begin{array}{l}1.23 \pm 0.06 \\
b, d, f\end{array}$ & $\begin{array}{l}1.40 \pm 0.08 \\
a, b, c, e\end{array}$ & $\begin{array}{l}1.24 \pm 0.06 \\
b, d, f\end{array}$ & $\begin{array}{l}1.41 \pm 0.07 \\
a, b, c, e\end{array}$ \\
\hline & $\begin{array}{l}\text { V50\%/NPTVs } \\
p<0.05\end{array}$ & $\begin{array}{l}2.55 \pm 0.33 \\
b, d, f\end{array}$ & $\begin{array}{l}2.94 \pm 0.41 \\
\mathrm{a}, \mathrm{c}, \mathrm{d}, \mathrm{e}, \mathrm{f}\end{array}$ & $\begin{array}{l}2.49 \pm 0.19 \\
b, d, e, f\end{array}$ & $\begin{array}{l}2.79 \pm 0.25 \\
a, b, c, e\end{array}$ & $\begin{array}{l}2.52 \pm 0.21 \\
b, c, d, f\end{array}$ & $\begin{array}{l}2.84 \pm 0.29 \\
a, b, c, e\end{array}$ \\
\hline & $\begin{array}{l}\text { V10\%NPTVs } \\
p<0.05\end{array}$ & $\begin{array}{l}9.31 \pm 1.89 \\
b, d, f\end{array}$ & $\begin{array}{l}9.55 \pm 1.90 \\
a, c, d, e, f\end{array}$ & $\begin{array}{l}9.28 \pm 1.84 \\
b, d, f\end{array}$ & $\begin{array}{l}9.41 \pm 1.81 \\
a, b, c, e\end{array}$ & $\begin{array}{l}9.28 \pm 1.81 \\
b, d, f\end{array}$ & $\begin{array}{l}9.39 \pm 1.78 \\
a, b, c, e\end{array}$ \\
\hline Right Parotid & $\begin{array}{l}\mathrm{D}_{\text {Mean }}<24 \mathrm{~Gy} \\
p<0.05\end{array}$ & $\begin{array}{l}24.8 \pm 5.8 \\
b, d, e, f\end{array}$ & $\begin{array}{l}19.1 \pm 4.4 \\
a, c, f\end{array}$ & $\begin{array}{l}24.2 \pm 5.4 \\
b, d, e, f\end{array}$ & $\begin{array}{l}18.4 \pm 4.7 \\
a, c, f\end{array}$ & $\begin{array}{l}19.0 \pm 5.9 \\
a, c, f\end{array}$ & $\begin{array}{l}17.1 \pm 5.0 \\
a, b, c, d, e\end{array}$ \\
\hline \multirow[t]{2}{*}{ Total Fails } & Parameters & 22 & 2 & 20 & 4 & 11 & 3 \\
\hline & Plans & 13 & 2 & 13 & 3 & 7 & 2 \\
\hline
\end{tabular}

Comparisons are based on the Wilcoxon signed-rank test and significant differences ( $p$-value $<0.05$ ) between planning methods are indicated with the letters. The last two rows show the number of plans in each group that failed to meet all the constraints and the number of parameters that were violated within them

As a result of this observation the two plans with the lowest MF from each of these plan categories $\left(\mathrm{RP} \_1+\mathrm{TO}, \mathrm{RP}-\mathrm{TO}\right.$, and $\left.\mathrm{RP}_{-} \mathrm{TO}^{+}\right)$were selected for plan specific QA. Table 4 presents the analysis of the plan QA including the percentage of points passing the gamma criteria for each of them and also for their corresponding clinical plan for reference. All the plans subject to QA were reported deliverable according to the acceptance criteria given above.

\section{Discussion}

In this study, the combined use of RP and TO was proposed focusing on HNC radiotherapy VMAT planning. Three workflows were followed using RP together with $\mathrm{TO}$ during the optimisation process: the use of an in- house RP model built with TO VMAT plans (RP_TO); the use of an in-house RP model, built with clinical VMAT plans, to obtain the starting optimisation objectives parameters and then further TO (RP_1+TO); and the use of 


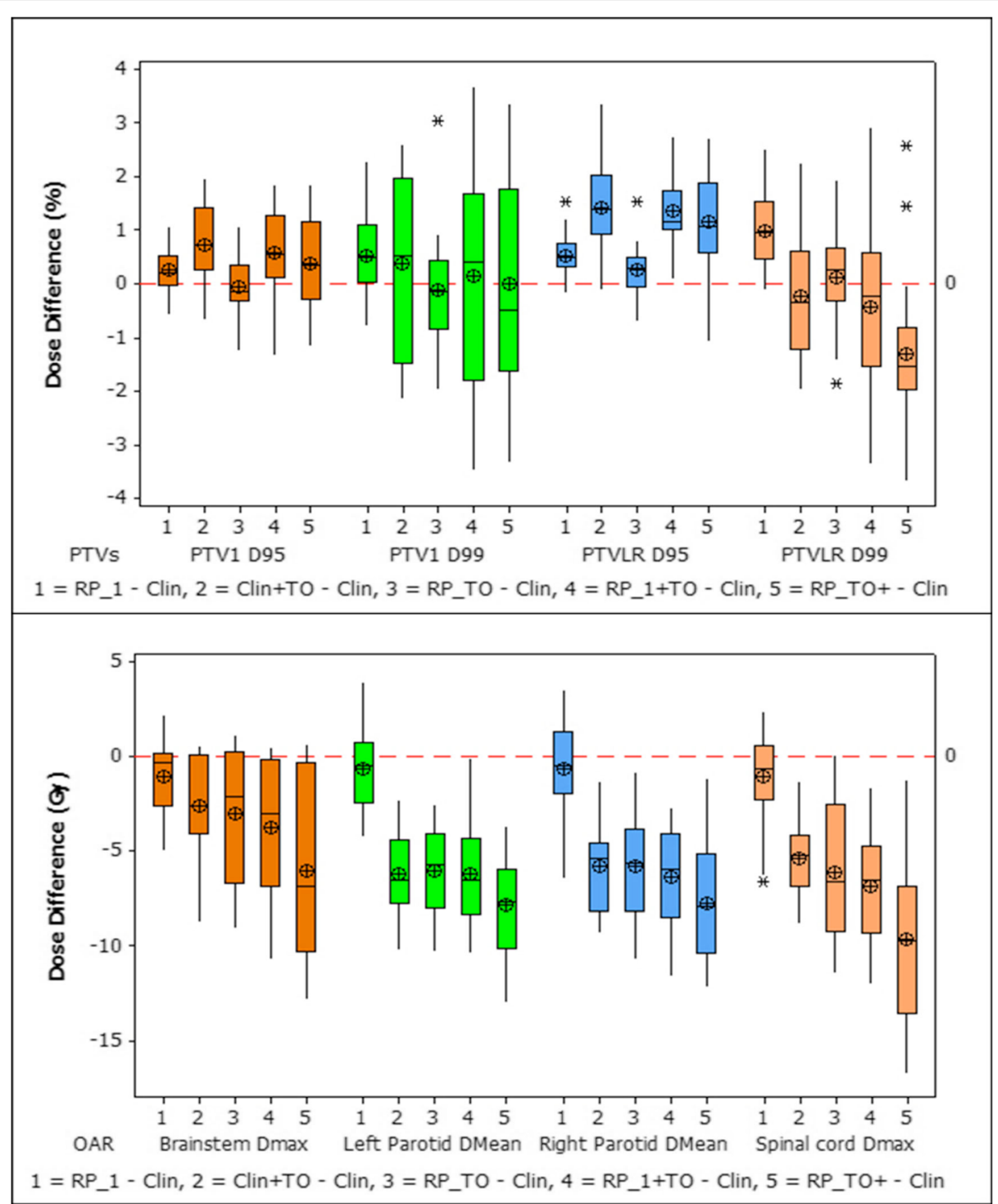

Fig. 2 Box plot of the difference of dosimetric parameters (PTVs-above and OAR-below) between clinical and generated plans. The mean value is indicated by the $\oplus$ symbol, the median value by the central horizontal line, the interquartile range is represented by the box, and the outliers are indicated by the asterisks

RP_TO to generate the initial objectives parameters and further TO (RP_TO ${ }^{+}$. The dosimetric impact was assessed on the resulting plans for a set of 20 patients. In addition, for each patient, two more plans were created using $\mathrm{TO}$ and $\mathrm{RP}$ on its own during the optimisation stage (Clin+TO, RP_1). For the five optimisation strategies and the clinical plans, a dosimetric comparison across the resulting plans was carried out. Additionally, investigation of complexity and deliverability of the plans was performed.

Although the use of RP and TO separately presents advantages over the clinical plans [11, 19], it was shown that for this treatment the combined use of both optimisation methods improves the relationship between balancing OAR doses and PTV coverage, i.e. while maintaining comparable clinically acceptable target coverage, the resulting plans reduced the OAR doses. It was demonstrated that the RP models are able to provide a semi-automatic suggestion of a plan that is a good start for TO. The OAR doses of the plans generated by the RP_TO model, built with previously $\mathrm{TO}$ optimised plans, reflect its benefit over the RP_1 model. Therefore, this approach suggests being convenient for centres that does not have TO but that can implement shared RP 


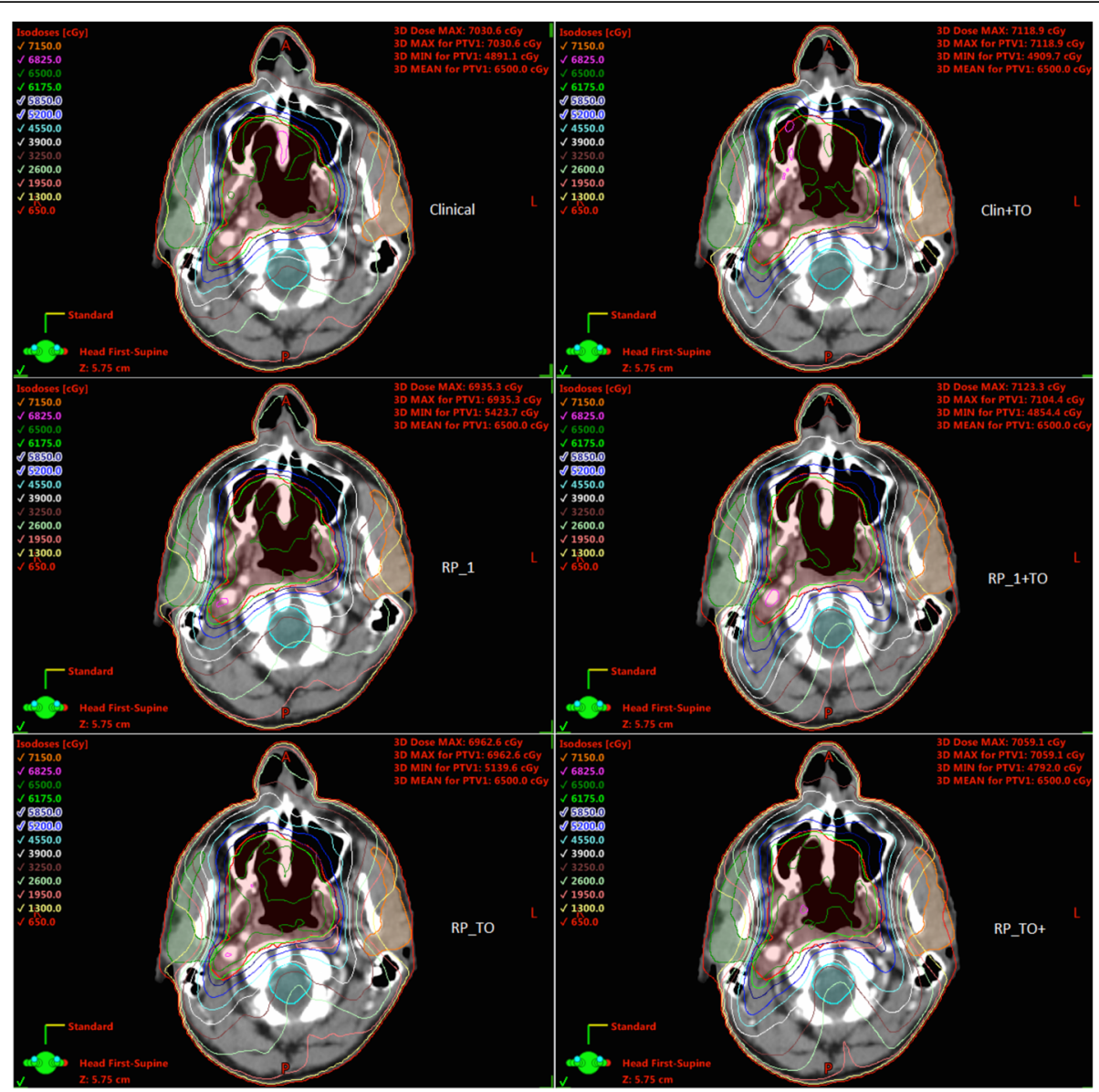

Fig. 3 Dose distribution at the parotids level for a representative case resulting from each planning optimisation procedure

models. When comparing RP_TO and RP_1+TO plans no significant difference was reported on OAR sparing, but the first one reduced active planner interaction. Furthermore, when RP_TO is used as the initial plan with subsequent use of $\mathrm{TO}\left(\mathrm{RP}_{-} \mathrm{TO}^{+}\right)$ this led to the largest dose reduction for all OAR. This reveals that for a new patient, the knowledge-based model that was trained with the plans that were already optimised by TO helped to obtain optimisation parameters that are closer to the desired trade-offs, providing the best starting point for TO. The results are in agreement with Wang J et al. [17] who showed for nasopharyngeal treatments that choosing better optimisation parameters for a plan with the aid of automated planning prior to use MCO led to improved plans.

$\mathrm{RP}_{-} \mathrm{TO}^{+}$plans achieved the lowest average OAR doses for all the dose-volume parameters investigated. Most notably, a significant reduction in mean dose of $7.9 \mathrm{~Gy}$ and $7.7 \mathrm{~Gy}$ for the left and right parotids respectively was accomplished with respect to the clinical plans. Despite the dose improvement for the OAR, the CI results showed that the dose to normal tissue was slightly compromised. Further work with NTO and the inclusion of a structure, considering normal tissue not being recognised as OAR, as part of the trade-offs exploration objectives is of our interest to investigate improvement [19]. On the contrary, OAR doses with RP_TO plans are higher than with $\mathrm{RP}_{-} \mathrm{TO}^{+}$but this plans provided an OAR dose improvement respect to clinical plans while maintaining comparable $\mathrm{CI}$ and $\mathrm{HI}$ to them, being this influenced by the upper PTVLR objectives used in the RP model. The results from both workflows point to the capacity of $\mathrm{TO}$ to decide on the trade-offs pursued for this cohort of patients and agree with ongoing HNC trials that have shown decreased toxicity to the surrounding organs as a result of dose de-escalation to nodal PTV. The implementation of RP and TO for the treatment of this cohort of patients could lead to an improved patient quality of life [34, 35]. 

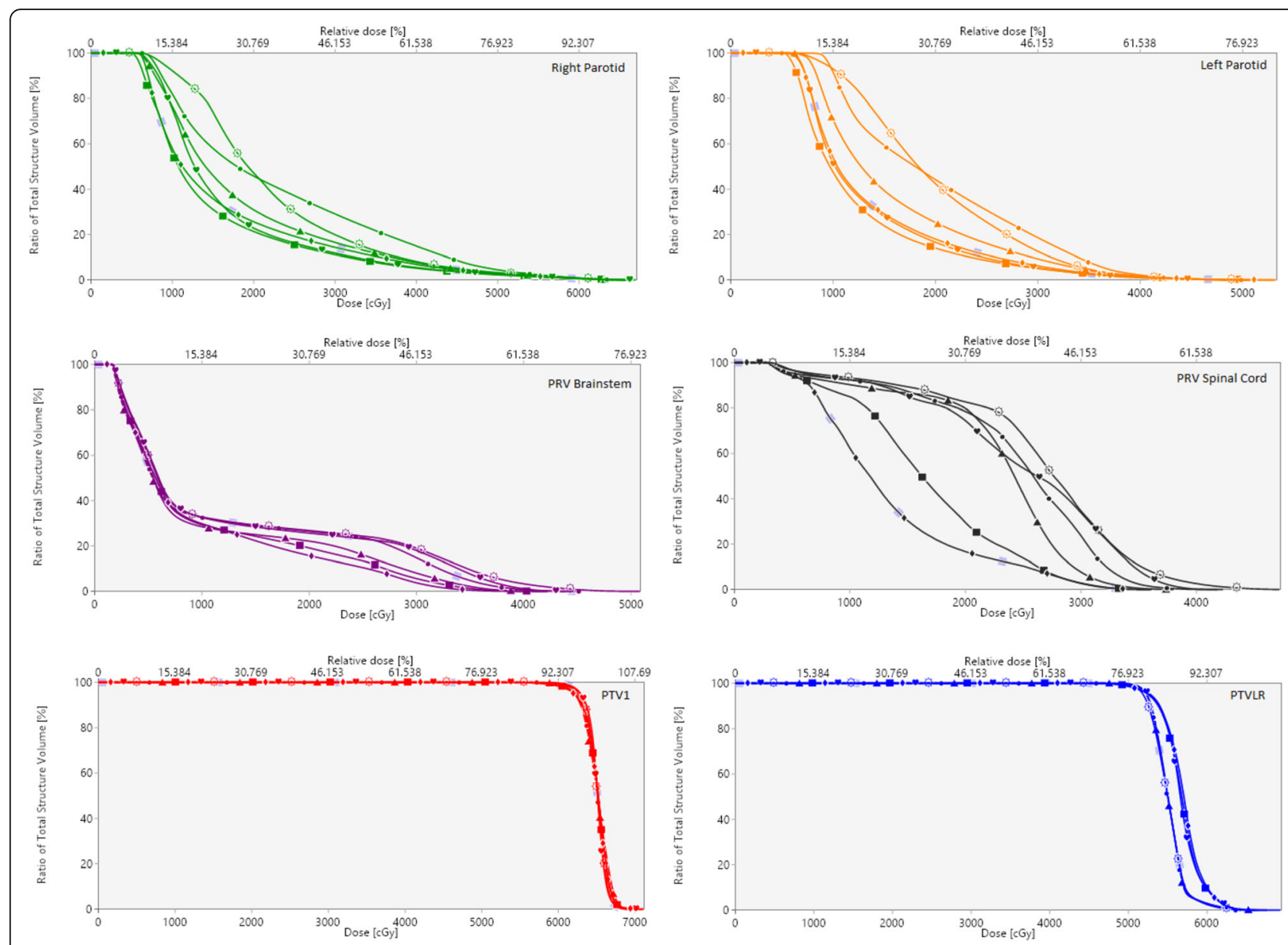

Fig. 4 DVHs corresponding to representative case shown in Fig. 3. Clinical (suns), Clinical+TO (hearts), RP_1 (circles), RP_1 + TO (rhombus), RP_TO (triangles), $\mathrm{RP}_{-} \mathrm{TO}^{+}$(squares)

The results displayed in Table 2 support the value of $\mathrm{TO}$ as a tool for attaining further individualised plan improvements. It is shown that the application of $\mathrm{TO}$ as the final step in planning (Clin+TO, RP_1 $+\mathrm{TO}$ and $\mathrm{RP}_{-} \mathrm{TO}^{+}$) resulted in a consistent reduced number of plans failing to meet the OAR constraints. The reason three plan parameters failed with RP_TO ${ }^{+}$as opposed to two with Clin+TO is that the additional failing plan had the largest PTV1 in the set $(1069.0 \mathrm{cc})$ and this lay outside the range of the plans that constitute the RP models used; therefore, following our trade-offs management, PTV1 $\mathrm{D}_{99}$ and PTVLR $\mathrm{D}_{99}$ were marginally below the constraint (94.9 and $74.7 \%$ respectively). This patient was re-planned with different trade-offs exploration management and the constraints of the PTVs were

Table 3 Complexity parameters for each group of plans (average and range)

\begin{tabular}{|c|c|c|c|c|c|c|}
\hline & a - Clinical & b - Clinical + TO & c-RP_1 & $d-R_{-} \_1+T O$ & e - RP_TO & $f-\mathrm{RP}_{-} \mathrm{TO}^{+}$ \\
\hline $\begin{array}{l}\mathrm{ALPO}(\mathrm{cm}) \\
p<0.05\end{array}$ & $\begin{array}{l}3.37(2.54-5.40) \\
c, d, e, f\end{array}$ & $\begin{array}{l}3.39(2.46-5.99) \\
\text { d,e,f }\end{array}$ & $\begin{array}{l}3.16(2.42-4.83) \\
a, e, f\end{array}$ & $\begin{array}{l}3.04(2.45-5.34) \\
a, b, e, f\end{array}$ & $\begin{array}{l}2.72(1.89-4.19) \\
a, b, c, d, f\end{array}$ & $\begin{array}{l}2.89(2.16-4.60) \\
a, b, c, d, e\end{array}$ \\
\hline $\begin{array}{l}\text { MF } \\
p<0.05\end{array}$ & $\begin{array}{l}0.477(0.347-0.574) \\
\text { d,e,f }\end{array}$ & $\begin{array}{l}0.467(0.345-0.562) \\
d, e, f\end{array}$ & $\begin{array}{l}0.461(0.390-0.503) \\
\text { d,e,f }\end{array}$ & $\begin{array}{l}0.430(0.361-0.519) \\
a, b, c, e\end{array}$ & $\begin{array}{l}0.405(0.366-0.446) \\
a, b, c, d\end{array}$ & $\begin{array}{l}0.414(0.379-0.464) \\
a, b, c\end{array}$ \\
\hline $\begin{array}{l}\mathrm{MU} \\
p<0.05\end{array}$ & $\begin{array}{l}489(399-652) \\
d, e, f\end{array}$ & $\begin{array}{l}501(407-662) \\
d, e, f\end{array}$ & $\begin{array}{l}501(453-568) \\
d, e, f\end{array}$ & $\begin{array}{l}541(456-647) \\
a, b, c, e\end{array}$ & $\begin{array}{l}571(497-622) \\
a, b, c, d\end{array}$ & $\begin{array}{l}560(478-603) \\
a, b, c\end{array}$ \\
\hline
\end{tabular}

Average leaf pair opening (ALPO), Modulation Factor (MF) and total number of Monitor Units (MU). Significant differences ( $p$-value $<0.05)$ between the planning methods are indicated with the letters 
Table 4 Percentage of points passing the $3 \% / 3 \mathrm{~mm}$ gamma

\begin{tabular}{llll} 
criteria & & & \\
\hline Patient & Plan & Pass rate (\%) Global & Pass rate (\%) Local \\
\hline 1 & Clinical & 99.7 & 95.1 \\
& RP_TO & 99.0 & 93.5 \\
2 & Clinical & 99.7 & 93.5 \\
& RP_TO & 99.4 & 94.6 \\
& RP_TO & 99.4 & 95.5 \\
3 & Clinical & 99.3 & 94.1 \\
& RP_TO & 98.9 & 94.7 \\
& RP_1+TO & 98.8 & 94.9 \\
4 & Clinical & 99.6 & 94.4 \\
& RP_1+TO & 99.2 & 94.4
\end{tabular}

Data for the six plans that reported the lowest MF and the clinical plan corresponding

met at the expense of a $2.4 \mathrm{~Gy}$ increase in the left parotid mean dose. This example points to the fact that the success of a RP model is dependent upon the quality and robustness of the model itself [20]. Similarly, in the use of TO there is an inherent element of user influence.

The time required to create these plans is equally of relevance. The estimated time in our clinics to plan a HNC case, including optimisation and dose calculation until the final plan is produced, ranges between 50 and 300 min depending on the complexity and the experience of the planner. The use of $\mathrm{RP}$ and $\mathrm{MCO}$ in clinical practice has proven to reduce planning time $[10,36]$. Following the proposed workflows, with the combined use of both approaches, the approximate time taken remained always under $80 \mathrm{~min}$, being affected mostly by the speed of the calculations and the number of optimisation objectives selected rather than by the human time needed or the planner experience. Therefore, using both RP and TO at the same time did not increase our human time at the console, and overall is expected to reduce it as less interaction to reach a clinically acceptable solution is needed.

Kyroudi, et al. [37] reported dosimetric differences between the exploration of the alternative plans generated with MCO and the deliverable plans that are created after this, which take into account physical treatment unit restrictions. In this study, small discrepancies were noticed as well but they were followed by a repetition of the trade-off exploration only in a few cases when we were already in the limit of the dose required to meet the
PTVs constraints. Furthermore, an evaluation of the dosimetric delivery parameters was performed to warranty plan deliverability. It was found that the complexity of the plans increased when using RP and TO together. This could be expected as the sparing of the OAR has been improved providing higher quality plans [38]. The highest mean MU value and lowest mean MF and ALPO values were observed for the RP_TO plans suggesting that these plans are more complex than the $\mathrm{RP}_{-} 1+\mathrm{TO}$ and $\mathrm{RP}_{-} \mathrm{TO}^{+}$. Although $\mathrm{RP}_{-} \mathrm{TO}^{+}$showed better relationship between OAR sparing and PTV coverage, it can be observed that the homogeneity of the targets is slightly better when using RP_TO which has proved to have relation with an increase in complexity [39]. Despite the higher complexity of the plans that used $\mathrm{RP}$ and TO, the observed values were within the range of the clinical plans. Further, for the extreme values of the three proposed workflows, in most cases the results from the gamma evaluation showed improvement on the agreement of the delivered and planned dose to the OAR, and concluded that the plans are deliverable clinically.

Future work will focus on the implementation of the RP_TO and $\mathrm{RP}_{-} \mathrm{TO}^{+}$workflows in clinical practice and analysis of the physicians' preference on the resulting trade-offs. The use of the proposed optimisation approaches for other treatment sites is of interest and the opportunity to use RP and TO in combination to escalate the dose delivered to the tumour while maintaining or reducing OAR doses.

\section{Conclusions}

The use of RP combined with TO improved OAR sparing on VMAT HNC radiotherapy plans while maintaining clinically acceptable target coverage. The simultaneous use of both approaches reflects in the resulting plans the individual benefit that they provide. The best OAR sparing was obtained when planning starting by generating a plan with a RP model built with plans optimised with TO and then further individualised TO optimisation. For this workflow, the trade-off between a minor deterioration of the nodal PTV, while maintaining clinically acceptable PTVs coverage, allowed the most significant reduction in OAR doses. RP_TO plans, created with the RP model optimised with TO plans, also provided an OAR dose improvement respect to clinical plans while maintaining comparable conformity and target homogeneity. Plans optimised with RP and TO were proven to be deliverable despite an increase in plan modulation. 


\section{Appendix}

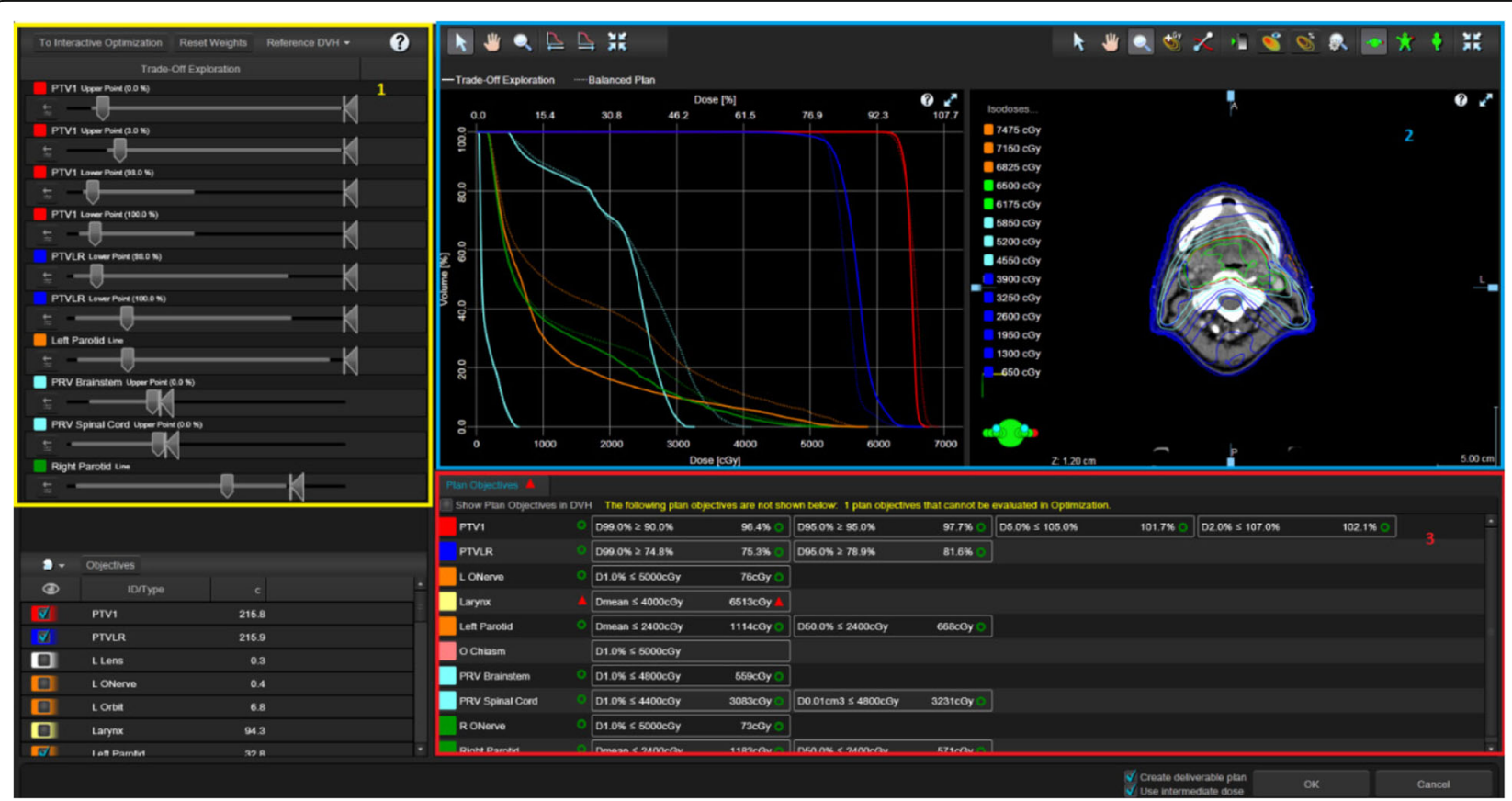

Fig. 5 Eclipse real time plan navigation screen view during TO for one of the head and neck plans. 1-Yellow box: Trade-Offs exploration with slider bars for each selected objective. 2-Blue box: Graphical feedback of the modifications instantly monitored in the DVHs and the dose distribution view displayed. 3-Red box: Plan objectives displaying the protocol constraints for dose-volume monitoring

Table 5 Structures and Objectives used for the RapidPlan models. The rest of the OAR (Lenses, Optic Nerves, Orbits, Optic Chiasm, Larynx, Parotids and Trachea) have only a Line (preferring target) objective with volume, dose and priority Generated

\begin{tabular}{llll}
\hline & Volume (\%) & Dose (cGy) & Priority \\
\hline PTV 1 - Upper & 0 & 6800 & 110 \\
PTV 1 - Upper & 3 & 6700 & 110 \\
PTV 1 - Lower & 98 & 6350 & 110 \\
PTV 1 - Lower & 100 & 6250 & 110 \\
PTVLR - Upper & 1 & 6300 & 110 \\
PTVLR - Upper & 5 & 5700 & 110 \\
PTVLR - Upper & 50 & 5400 & 65 \\
PTVLR - Lower & 98 & 5300 & 110 \\
PTVLR - Lower & 100 & 5200 & 120 \\
PRV Brainstem Upper & 0 & 4500 & 150 \\
PRV Brainstem - Line (preferring target) & Generated & Generated & Generated \\
PRV Spinal cord - Upper & 0 & 4500 & 150 \\
PRV Spinal cord - Line (preferring target) & Generated & Generated \\
\hline
\end{tabular}


Table 6 Number of parameter violations occurred in each group of head and neck plans

\begin{tabular}{|c|c|c|c|c|c|c|c|}
\hline Structure & Parameter & a - Clinical & $\mathrm{b}-\mathrm{Clin}+\mathrm{TO}$ & $c-R P_{-} 1$ & $d-R_{-} 1+T O$ & e - RP_TO & $f-\mathrm{RP}_{-} \mathrm{TO}^{+}$ \\
\hline \multirow[t]{4}{*}{$\overline{\text { PTV } 1}$} & $D_{99}>90 \%$ & 0 & 0 & 0 & 2 & 1 & 0 \\
\hline & $D_{95}>95 \%$ & 1 & 0 & 1 & 1 & 2 & 1 \\
\hline & $D_{5 \%}<105 \%$ & 0 & 0 & 0 & 0 & 0 & 0 \\
\hline & $D_{2 \%}<107 \%$ & 0 & 0 & 0 & 0 & 0 & 0 \\
\hline \multirow[t]{2}{*}{ PTV LR } & $D_{99 \%}>74.8 \%$ & 0 & 0 & 0 & 0 & 1 & 1 \\
\hline & $D_{95 \%}>78.9 \%$ & 1 & 0 & 0 & 0 & 1 & 0 \\
\hline PRV Brainstem & $\mathrm{D}_{\operatorname{Max}}<48 \mathrm{~Gy}$ & 0 & 0 & 0 & 0 & 0 & 0 \\
\hline \multirow[t]{2}{*}{ PRV Spinal Cord } & $\mathrm{D}_{1 \%}<44 \mathrm{~Gy}$ & 0 & 0 & 0 & 0 & 0 & 0 \\
\hline & $\mathrm{D}_{\operatorname{Max}}<48 \mathrm{~Gy}$ & 0 & 0 & 0 & 0 & 0 & 0 \\
\hline Left Parotid & $D_{\text {Mean }}<24 G y$ & 10 & 0 & 8 & 0 & 1 & 0 \\
\hline Right Parotid & $D_{\text {Mean }}<24 G y$ & 10 & 2 & 11 & 1 & 5 & 1 \\
\hline \multirow[t]{2}{*}{ Total Fails } & Parameters & 22 & 2 & 20 & 4 & 11 & 3 \\
\hline & Plans & 13 & 2 & 13 & 3 & 7 & 2 \\
\hline
\end{tabular}

Table 7 Mean doses received for larynx and trachea by each planning method when PTV did not originate in these sites

\begin{tabular}{|c|c|c|c|c|c|c|c|}
\hline Structure & Parameter & a - Clinical & $\mathrm{b}-\mathrm{Clin}+\mathrm{TO}$ & $c-R P_{-} 1$ & $\mathrm{~d}-\mathrm{RP}_{-} 1+\mathrm{TO}$ & e-RP_TO & $f-\mathrm{RP}_{-} \mathrm{TO}^{+}$ \\
\hline Larynx & $\begin{array}{l}D_{\text {Mean }}<40 G y \\
p<0.05\end{array}$ & $\begin{array}{l}42.0 \pm 7.2 \\
d, e, f\end{array}$ & $39.8 \pm 8.3$ & $\begin{array}{l}41.7 \pm 6.9 \\
d, e\end{array}$ & $\begin{array}{l}38.4 \pm 8.8 \\
a, c\end{array}$ & $\begin{array}{l}37.1 \pm 7.0 \\
a, c\end{array}$ & $\begin{array}{l}39.6 \pm 7.8 \\
a\end{array}$ \\
\hline Trachea & $\begin{array}{l}D_{\text {Mean }}-N / S \\
p<0.05\end{array}$ & $\begin{array}{l}34.8 \pm 6.8 \\
b, c, e, f\end{array}$ & $\begin{array}{l}37.4 \pm 6.2 \\
a, c, d, e, f\end{array}$ & $\begin{array}{l}32.3 \pm 5.2 \\
a, b, d, e\end{array}$ & $\begin{array}{l}35.3 \pm 5.5 \\
b, c, e, f\end{array}$ & $\begin{array}{l}30.2 \pm 6.7 \\
a, b, c, d, f\end{array}$ & $\begin{array}{l}32.6 \pm 6.0 \\
a, b, d, e\end{array}$ \\
\hline
\end{tabular}

\section{Abbreviations}

ALPO: Average leaf pair opening; CTV: Clinical target volume; DTA: Distance to agreement; DVH: Dose-volume histogram; HI: Homogeneity index; HNC: Head and neck cancer; IMRT: Intensity modulated radiotherapy; MCO: Multi-criteria optimisation; MF: Modulation factor; MU: Monitor units; OAR: Organs at risk; PRV: Planning organ at risk volume; PTV: Planning target volume; PTV1: Main planning target volume; PTVLR: Low risk planning target volume; QA: Quality assurance; RP: RapidPlan; TO: Multi-Criteria Optimisationbased Trade-Off Exploration; TPS: Treatment planning system;

VMAT: Volumetric modulated arc therapy

\section{Acknowledgements}

The authors would like to thank Peter Houston and Susan Morris for the valuable comments to this work.

\section{Funding}

No funding

\section{Availability of data and materials}

The datasets used and analysed during the current study are available from the corresponding author on reasonable request.

\section{Authors' contributions}

Study design: GC, SC. Treatment cases planning: EM, GC, SC. Knowledgebased models construction: AJ, EM, GC, SC. Dosimetry measurements: AJ, EM. Data acquisition, statistical analysis and manuscript drafting: EM. Interpretation of data: AJ, EM, GC, SC. Manuscript editing: AJ, EM, GC, SC. All authors read and approved the final manuscript.

\section{Ethics approval and consent to participate}

Consent for the use of patients' data for retrospective and scientific investigation.

\section{Consent for publication}

Consent for the use of patients' data for retrospective and scientific investigation.

\section{Competing interests}

The authors declare that they have no competing interests.

\section{Publisher's Note}

Springer Nature remains neutral with regard to jurisdictional claims in published maps and institutional affiliations.

Received: 14 August 2018 Accepted: 6 November 2018

Published online: 23 November 2018

\section{References}

1. Cooper JS, Fu K, Marks J, Silverman S. Late effects of radiation therapy in the head and neck region. Int J Radiat Oncol Biol Phys. 1995;31:1141-64.

2. Langendijk JA, Doornaert P, Verdonck-de Leeuw IM, Leemans CR, Aaronson NK, Slotman BJ. Impact of late treatment-related toxicity on quality of life among patients with head and neck cancer treated with radiotherapy. J Clin Oncol. 2008;26:3770-6.

3. Deasy JO, Moiseenko V, Marks L, Chao KC, Nam J, Eisbruch A. Radiotherapy dose-volume effects on salivary gland function. Int J Radiat Oncol Biol Phys. 2010;76:S58-63.

4. Holt A, Van Gestel D, Arends MP, Korevaar EW, Schuring D, Kunze Busch $\mathrm{MC}$, et al. Multi-institutional comparison of volumetric modulated arc therapy vs. intensity-modulated radiation therapy for head-and-neck cancer: a planning study. Radiat Oncol. 2013;8:26.

5. Verbakel WF, Cuijpers JP, Hoffmans D, Bieker M, Slotman BJ, Senan S. Volumetric intensity-modulated arc therapy vs. conventional IMRT in headand-neck cancer: a comparative planning and dosimetric study. Int J Radiat Oncol Biol Phys. 2009;74:252-9. 
6. Vanetti E, Clivio A, Nicolini G, Fogliata A, Ghosh-Laskar S, Agarwal JP. Et at Volumetric modulated arc radiotherapy for carcinomas of the oro-pharynx, hypo-pharynx and larynx: a treatment planning comparison with fixed field IMRT. Radiother Oncol. 2009;92:111-7.

7. Clemente S, Wu B, Sanguineti G, Fusco V, Ricchetti F, Wong J, et al. SmartArcbased volumetric modulated arc therapy for oropharyngeal cancer: a dosimetric comparison with both intensity-modulated radiation therapy and helical tomotherapy. Int J Radiat Oncol Biol Phys. 2011;80:1248-55.

8. Craft DL, Halabi TF, Shih HA, Bortfeld TR. Approximating convex Pareto surfaces in multiobjective radiotherapy planning. Med Phys. 2006;33: 3399-407.

9. Craft D, McQuaid D, Wala J, Chen W, Salari E, Bortfeld T. Multicriteria VMAT optimization. Med Phys. 2012;39:686-96

10. Craft DL, Hong TS, Shih HA, Bortfeld TR. Improved planning time and plan quality through multicriteria optimization for intensity-modulated radiotherapy. Int J Radiat Oncol Biol Phys. 2012;82:e83-90.

11. Kierkels RG, Visser R, Bijl HP, Langendijk JA, Veld v't, AA SRJ, et al. Multicriteria optimization enables less experienced planners to efficiently produce high quality treatment plans in head and neck cancer radiotherapy. Radiat Oncol. 2015;10:87.

12. Wala J, Craft D, Paly J, Zietman A, Efstathiou J. Maximizing dosimetric benefits of IMRT in the treatment of localized prostate cancer through multicriteria optimization planning. Med Dosimetry. 2013;38:298-303.

13. Kamran SC, Mueller BS, Paetzold P, Dunlap J, Niemierko A, Bortfeld T, et al. Multi-criteria optimization achieves superior normal tissue sparing in a planning study of intensity-modulated radiation therapy for RTOG 1308-eligible non-small cell lung cancer patients. Radiother Oncol. 2016; 118:515-20

14. Müller BS, Shih HA, Efstathiou JA, Bortfeld T, Craft D. Multicriteria plan optimization in the hands of physicians: a pilot study in prostate cancer and brain tumors. Radiat Oncol. 2017;12:168.

15. Thieke C, Küfer KH, Monz M, Scherrer A, Alonso F, Oelfke U, et al. A new concept for interactive radiotherapy planning with multicriteria optimization: first clinical evaluation. Radiother Oncol. 2007;85:292-8.

16. Varian Medical Systems, Inc. Eclipse photon and Electron algorithms reference guide. Palo Alto CA; 2017. p.221-31.

17. Wang J, Chen Z, Li W, Qian W, Wang X, Hu W. A new strategy for volumetric-modulated arc therapy planning using AutoPlanning based multicriteria optimization for nasopharyngeal carcinoma. Radiat Oncol. 2018;13:94.

18. Tol JP, Delaney AR, Dahele M, Slotman BJ, Verbakel WF. Evaluation of a knowledge-based planning solution for head and neck cancer. Int J Radiat Oncol Biol Phys. 2015;91:612-20.

19. Fogliata A, Reggiori G, Stravato A, Lobefalo F, Franzese C, Franceschini D, et al. RapidPlan head and neck model: the objectives and possible clinical benefit. Radiat Oncol. 2017;12:73.

20. Hussein M, South CP, Barry MA, Adams EJ, Jordan TJ, Stewart AJ, et al. Clinical validation and benchmarking of knowledge-based IMRT and VMAT treatment planning in pelvic anatomy. Radiother Oncol. 2016;120:473-9.

21. Nutting CM, Morden JP, Harrington KJ, Urbano TG, Bhide SA, Clark C, et al. Parotid-sparing intensity modulated versus conventional radiotherapy in head and neck cancer (PARSPORT): a phase 3 multicentre randomised controlled trial. Lancet Oncol. 2011;12:127-36.

22. Urbano MG, Clark CH, Kong C, Miles E, Dearnaley DP, Harrington KJ, et al. Target volume definition for head and neck intensity modulated radiotherapy: pre-clinical evaluation of PARSPORT trial guidelines. Clinical Oncol. 2007:19:604-13.

23. Varian Medical Systems, Inc. TPS New Features Workbook 15.5: users manual for Varian treatment planning software. Palo Alto: Varian Medical Systems, Inc; 2017. p. 104-15.

24. Bjordal K, Kaasa S, Mastekaasa A. Quality of life in patients treated for head and neck cancer: a follow-up study 7 to 11 years after radiotherapy. Int J Radiat Oncol Biol Phys. 1994;28:847-56.

25. Harrison LB, Zelefsky MJ, Pfister DG, Carper E, Raben A, Kraus DH, et al. Detailed quality of life assessment in patients treated with primary radiotherapy for squamous cell cancer of the base of the tonque. Head \& Neck. 1997;19:169-75.

26. Malouf JG, Aragon C, Henson BS, Eisbruch A, Ship JA. Influence of parotidsparing radiotherapy on xerostomia in head and neck cancer patients. Cancer Detect Prev. 2003:27:305-10.
27. Fogliata A, Belosi F, Clivio A, Navarria P, Nicolini G, Scorsetti M, et al. On the pre-clinical validation of a commercial model-based optimisation engine: application to volumetric modulated arc therapy for patients with lung or prostate cancer. Radiother Oncol. 2014;113:385-91.

28. Kataria T, Sharma K, Subramani V, Karrthick KP, Bisht SS. Homogeneity index: an objective tool for assessment of conformal radiation treatments. J Med Phys/Association of Medical Physicists of India. 2012;37:207.

29. Feuvret L, Noël G, Mazeron JJ, Bey P. Conformity index: a review. Int J Radiat Oncol Biol Phys. 2006;64:333-42.

30. Svensson E. Evaluation of complexity and deliverability of IMRT-treatment plans (Master thesis). Göteborg: The Sahlgrenska Academy; 2011.

31. Olofsson N. Evaluation of IMRT beam complexity metrics to be used in the IMRT QA process (Master thesis). Göteborg: The Sahlgrenska Academy; 2011

32. Syamkumar SA, Padmanabhan S, Sukumar P, Nagarajan V. Characterization of responses of $2 \mathrm{~d}$ array seven 29 detector and its combined use with octavius phantom for the patient-specific quality assurance in rapidarc treatment delivery. Med Dosimetry. 2012;37:53-60.

33. Alber M, Broggi S, De Wagter C, Eichwurzel I, Engström P, Fiorino C, et al. Guidelines for the verification of IMRT. ESTRO booklet. 2008.

34. Nuyts S, Lambrecht M, Duprez F, Daisne JF, Van Gestel D, Van den Weyngaert $D$, et al. Reduction of the dose to the elective neck in head and neck squamous cell carcinoma, a randomized clinical trial using intensity modulated radiotherapy (IMRT). Dosimetrical analysis and effect on acute toxicity. Radiother Oncol. 2013:109:323-9.

35. Mirghani H, Amen F, Blanchard P, Moreau F, Guigay J, Hartl DM, et al. Treatment de-escalation in HPV-positive oropharyngeal carcinoma: ongoing trials, critical issues and perspectives. Int J Cancer. 2014;136:1494-503.

36. Chang AT, Hung AW, Cheung FW, Lee MC, Chan OS, Philips H, Cheng YT, $\mathrm{Ng}$ WT. Comparison of planning quality and efficiency between conventional and knowledge-based algorithms in nasopharyngeal cancer patients using intensity modulated radiation therapy. Int J Radiat Oncol Biol Phys. 2016;95:981-90.

37. Kyroudi A, Petersson K, Ghandour S, Pachoud M, Matzinger O, Ozsahin M, et al. Discrepancies between selected Pareto optimal plans and final deliverable plans in radiotherapy multi-criteria optimization. Radiother Oncol. 2016;120:346-8.

38. Craft $D$, Süss $P$, Bortfeld $T$. The tradeoff between treatment plan quality and required number of monitor units in intensity-modulated radiotherapy. Int Journal Radiat Oncol Biol Phys. 2007:67:1596-605.

39. Shen L, Chen S, Zhu X, Han C, Zheng X, Deng Z, et al. Multidimensional correlation among plan complexity, quality and deliverability parameters for volumetric-modulated arc therapy using canonical correlation analysis. J Radiat Research. 2018:59:207-15.

Ready to submit your research? Choose BMC and benefit from:

- fast, convenient online submission

- thorough peer review by experienced researchers in your field

- rapid publication on acceptance

- support for research data, including large and complex data types

- gold Open Access which fosters wider collaboration and increased citations

- maximum visibility for your research: over $100 \mathrm{M}$ website views per year

At $\mathrm{BMC}$, research is always in progress.

Learn more biomedcentral.com/submission 